\title{
Reconstrucción nasal total: a propósito de un caso
}

\section{Total nasal reconstruction: case report}

\author{
Serracanta Domènech, J.*, Vázquez Fernández, D.**, López Munné, D. ${ }^{* \star *}$, \\ Gornés Benejam, B. ${ }^{* * *}$, Suñol Sala, $X^{* * * *}$
}

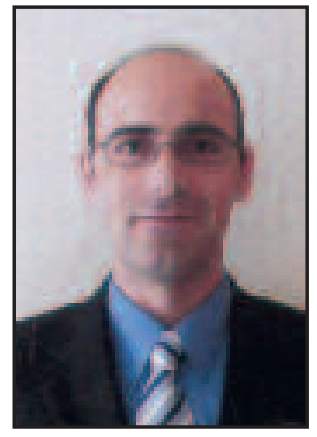

Serracanta Domènech, J.

\section{Resumen}

Presentamos el caso de una paciente de 90 años de edad afecta de un carcinoma escamoso nasal. Cualquier defecto a nivel nasal debe ser analizado en términos de pérdida anatómica de tejido y como subunidades estéticas, empezando en el defecto interno y progresando hacía afuera, plano por plano. El caso en cuestión muestra el uso de un colgajo septal, injertos óseos obtenidos de olécranon para el dorso, e injertos de cartílago conchal para recrear las dos alas nasales. Se precisaron dos colgajos nasolabiales y finalmente mediante un colgajo frontal se reconstruyó el defecto cutáneo en columela, dorso, alas y paredes nasales laterales. El pedículo se seccionó a las cuatro semanas.

Actualmente la paciente vive y sigue controles periódicos.

\author{
Palahras clave Reconstrucción nasal. Colgajo prefron- \\ tal. Carcinoma escamoso. \\ Código numérico 2444, 2421, 171
}

We present the case of a 90 year-old woman with a scamous cell carcinoma located on the nose. A nasal defect must be analyzed in terms of anatomic tissue loss and aesthetic three-dimensional subunits, starting from de inside of the nose and progressing outward, layer by layer. The case that follows demostrates the use of a septal pivot flap, an olecranum bone graft restored the dorsal subunit, and bilateral conchal cartilage grafts were fashioned into new alar cartilages. Bilateral nasolabial flaps were needed and finally the skin cover defect was resurfaced as a total nasal unit made of columela, dorsum, alar units and portions of the nasal sidewalls bilaterally with a forehead flap. Four weeks after the initial reconstruction, the forehead pedicle was divided.

At this moment the woman is alive and under periodical revision.

$\begin{array}{ll}\text { Key words } & \begin{array}{l}\text { Reconstruction of the nose. Forehead } \\ \text { flap. Scamous cel carcinoma. }\end{array} \\ \text { Numeral Gode } & 2444,2421,171\end{array}$

\footnotetext{
* $\quad$ Médico Adjunto de Cirugía Plástica, Reparadora y Estética. Hospital Universitario de Bellvitge. L'Hospitalet de Llobregat. Barcelona. España.

** Jefe Clínico de Cirugía Plástica, Reparadora y Estética. Hospital de Mataró (Consorci Sanitari del Maresme). Barcelona. España.

*** Médico Adjunto de Cirugía Plástica, Reparadora y Estética. Hospital de Mataró (Consorci Sanitari del Maresme). Barcelona. España.

**** Jefe del Servicio de Cirugía General. Hospital de Mataró (Consorci Sanitari del Maresme). Barcelona. España.
} 


\section{Introducción}

Las lesiones malignas más frecuentes en la piel de la cara consisten en carcinomas basocelulares, espinocelulares y melanomas; pueden encontrarse otras lesiones pero más raras, como el queratoacantoma, el tumor de células de Merkel y el carcinoma de glándulas sudoríparas (1). Es por eso que podemos extrapolar esta frecuencia de aparición de tipos tumorales a la piel nasal, zona de la cara que tratamos en este artículo a propósito de un caso de carcinoma espinocelular recidivado que precisó de amputación nasal total y reconstrucción posterior.

En el caso de que no se pueda realizar el cierre directo después de la exéresis simple en elipse, por haberse creado un defecto quirúrgico mayor, nos tendremos que decantar por una reconstrucción de grosor completo más adecuada. Los colgajos locales desde la vecindad inmediata del defecto son los más deseables (2), tanto desde el punto de vista funcional como estético. La irrigación sanguínea de la piel y las partes blandas faciales es extremadamente rica, ya que las ramas terminales de la arteria carótida externa constituyen un buen aporte. Los colgajos en la cara pueden basarse en vascularización aleatoria (romboidal, bilobulado y banner) o bien en vascularización axial (nasolabial, glabelar, frontal...).

La diseminación metastásica hacía los ganglios linfáticos regionales desde neoplasias malignas primarias del cuero cabelludo y de la cara es infrecuente. En general, los carcinomas espinocelulares con diámetro

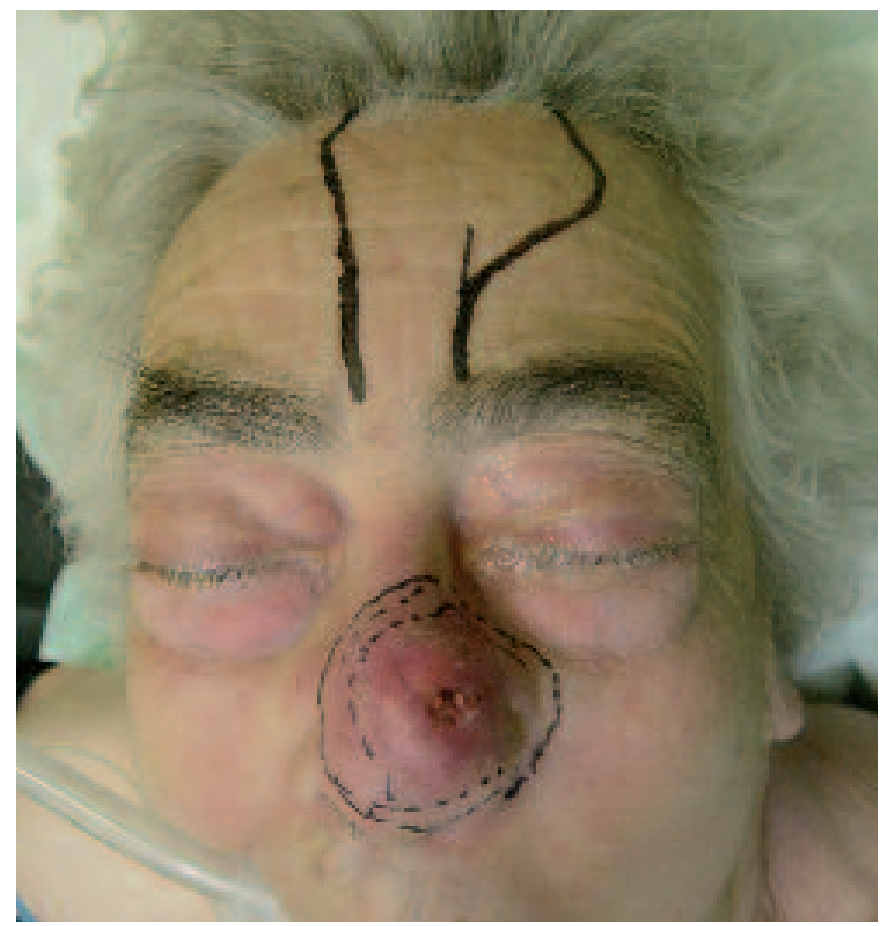

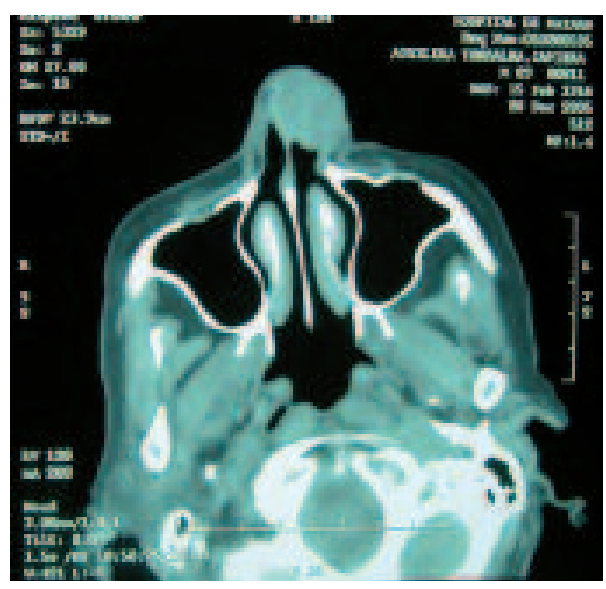

Fig. 1: Tomografia Axial Computerizada mostrando el tamaño, forma y localización de la recidiva a nivel nasal.

inferior a $2 \mathrm{~cm}$ conllevan un riesgo extremadamente bajo de metástasis, por tanto, no se recomienda el tratamiento programado de los ganglios linfáticos regionales. Las lesiones mayores de $2 \mathrm{~cm}$ tienen un riesgo proporcionalmente más alto de diseminación linfática regional. En general, la disección programada de los ganglios linfáticos regionales no ofrece ventajas terapéuticas significativas. Se observa una mejoría leve del pronóstico con la disección programada de los ganglios linfáticos regionales en el caso de melanomas malignos de grosor intermedio de origen cutáneo.

\section{CASO CLINICO}

Mujer de 89 años de edad que visita por primera vez nuestra consulta en Febrero de 2005, remitida desde Dermatología por presentar tumoración cutánea en ala

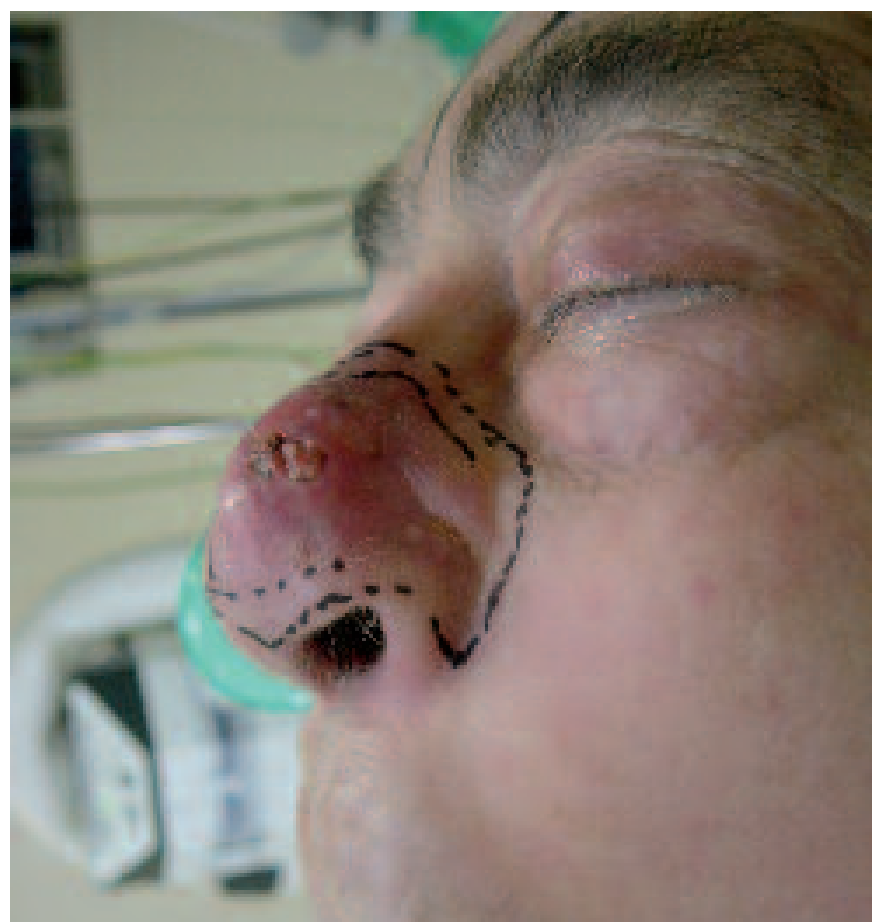

Fig.s 2a-b: Aspecto macroscópico de la recidiva a nivel nasal; marcaje de los márgenes de exéresis y de un colgajo frontal que no se llegó a usar en la primera intervención. 
nasal izquierda tratada en dos ocasiones mediante Crioterapia sin respuesta; no disponemos de fotos de esta fase inicial de la afección. Había presentado únicamente como signos clínicos epistaxis en tres ocasiones en Abril de 2003, cuando contaba 87 años de edad.

La Historia Clínica no refiere alergias medicamentosas conocidas; antecedentes patológicos de cardiopatía hipertensiva en tratamiento con Digoxina y arritmia por fibrilación auricular en tratamiento con Sintrom.

Dada la presentación clínica de la tumoración y la no respuesta a la terapia usada en dos ocasiones se decide realizar en Abril de 2005, una biopsia escisional de la lesión y cobertura mediante colgajo local Banner. El exámen anatomopatológico informa de carcinoma escamoso moderadamente diferenciado e infiltrante en tejido celular Los márgenes laterales de la exéresis están afectos. Dada la edad de la paciente y la patología asociada se decide control evolutivo de las posibles recidivas.Se procede a controles clínicos y por imagen mediante Tomografía Axial Computerizada (TAC) cada 3 meses.

La exploración realizada en Noviembre de 2005 notifica que no existen cambios significativos, existiendo una imagen nodular de atenuación de partes blandas en región nasal izquierda, sin variación en sus dimensiones ni morfología respecto a la TAC previa, sugestiva de cambios postcirugía mediante colgajo.

En Diciembre de 2005, en un nuevo control, la paciente refiere dolor en un margen del colgajo, con evidencia clínica de lesión papular eritematosa; se procede en la misma visita a practicar punch-biopsia, que informa de infiltración por carcinoma escamoso queratinizante. Se realiza nuevo estudio mediante TAC, en la que se aprecia aumento de tamaño y cam-

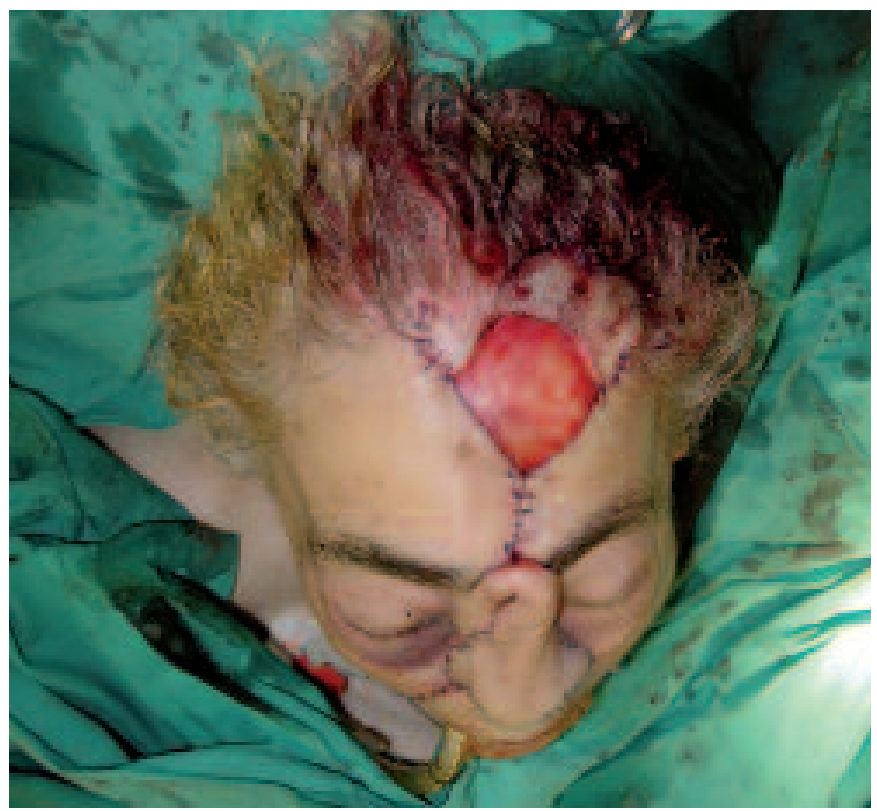

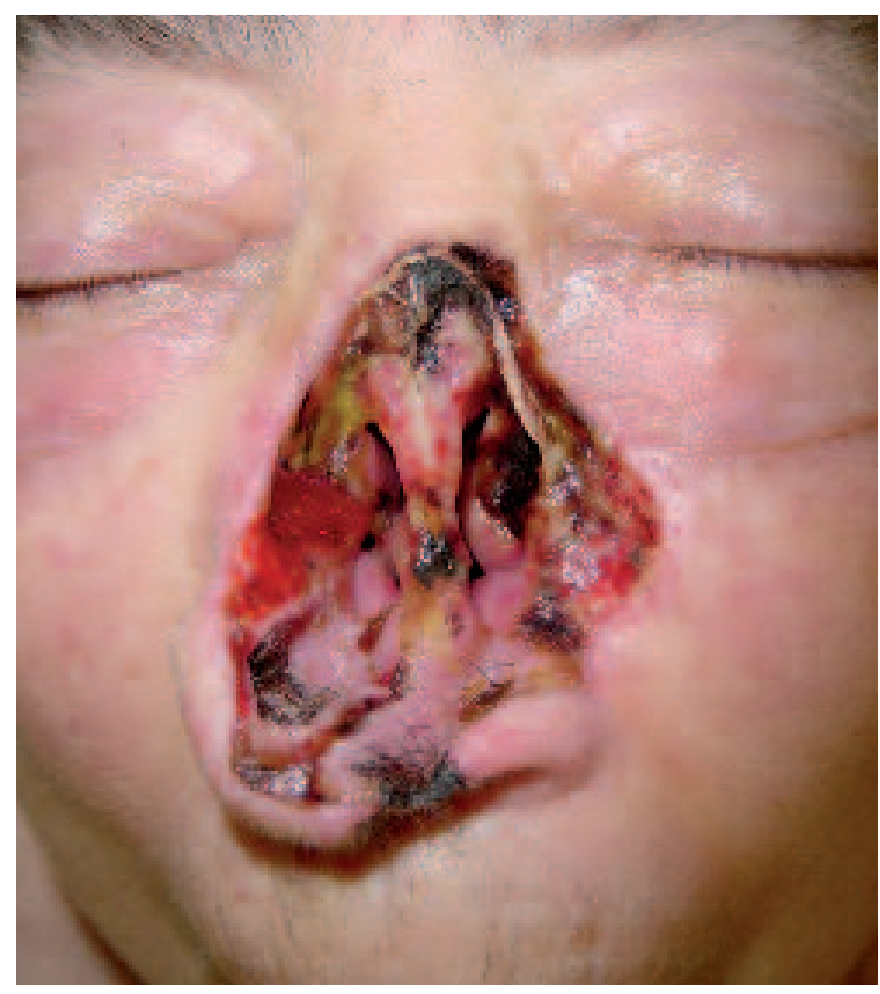

Fig. 3: Aspecto después de la amputación nasal primaria; imágenes previas a la cirugía de ampliación de márgenes afectos y reconstrucción nasal total.

bio de morfolgía de la imagen nodular previa, con proyección a nivel de fosa nasal (Fig.1).

Se procede a programar a la mayor brevedad posible la intervención de la recidiva, pero por falta de quirófano se pospone hasta Febrero; la lesión inicial biopsiada mediante punch ha aumentado rápidamente de tamaño, tal y como se aprecia en las fotografias previas a la cirugía (Fig.2).

Debido al tamaño de la lesión se decide proceder a amputación nasal total sin reconstrucción por el

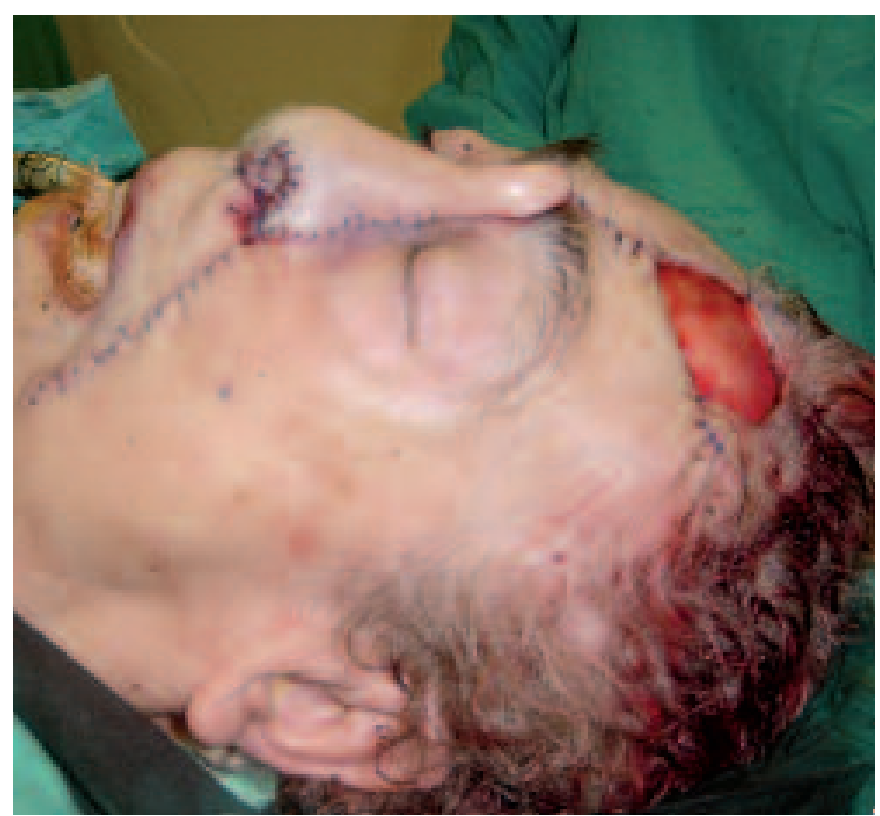

Fig. 4a-b: Resultado postoperatorio inmediato tras la reconstrucción nasal total. 

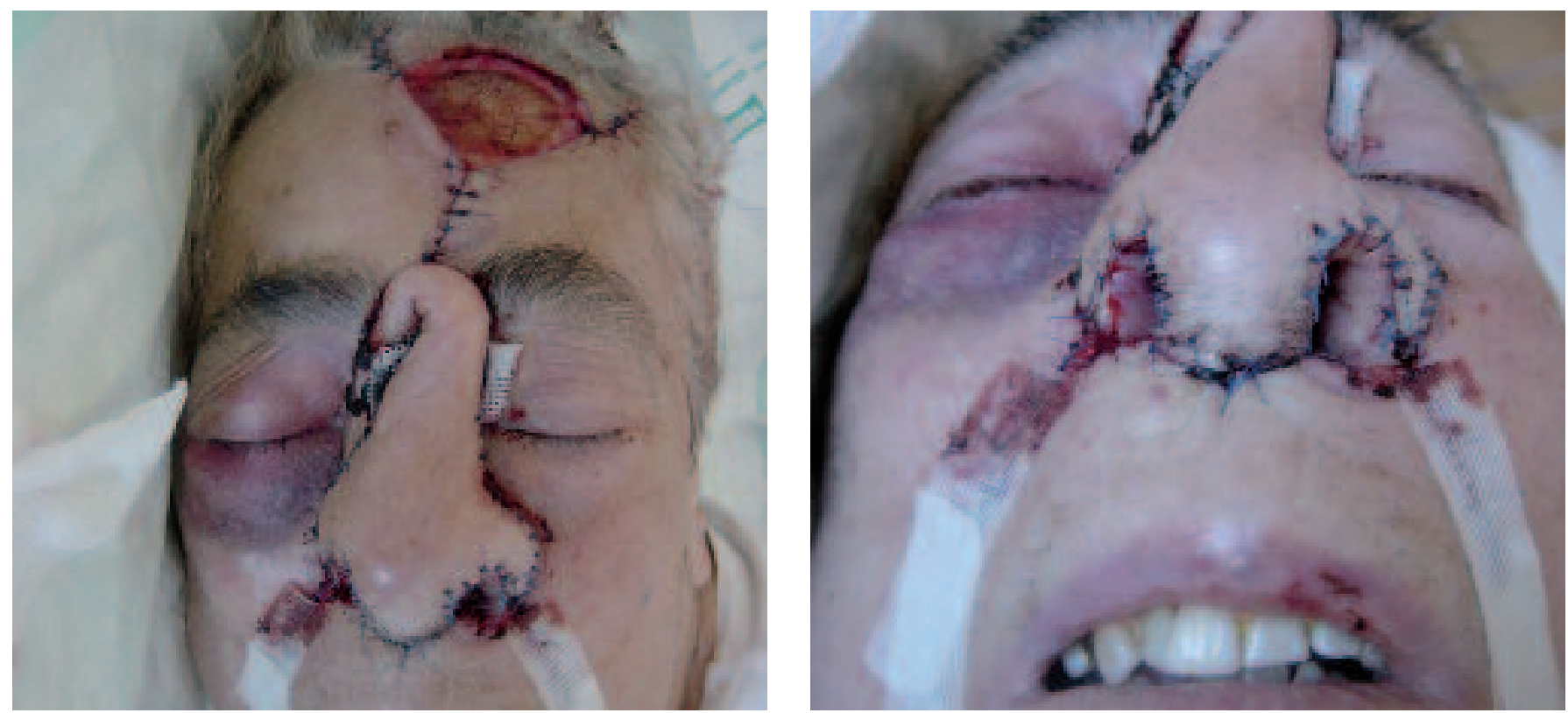

Fig. 5a-b: 24 horas de evolución; se aprecia la correcta perfusión del colgajo frontal de cobertura de toda la neoestructura nasal.

momento, dado el importante crecimiento de la lesión en poco tiempo y su extensión a tabique nasal, paredes laterales y parte cefálica de alas nasales.

Esta primera cirugía se realiza en unos 90 minutos, con buena toleracia por parte de la paciente. Basamos la decisión de no proceder a la reconstrucción inmediata en asegurar una correcta cirugía oncológica con márgenes libres (Fig. 3).

La Anatomía Patológica informa de carcinoma escamoso indiferenciado e infiltrante con afectación de márgenes a nivel de tabique nasal y alas nasales. Comentamos el caso con el Servicio de Anestesiología y Reanimación, pues la cirugía a realizar se puede alar-

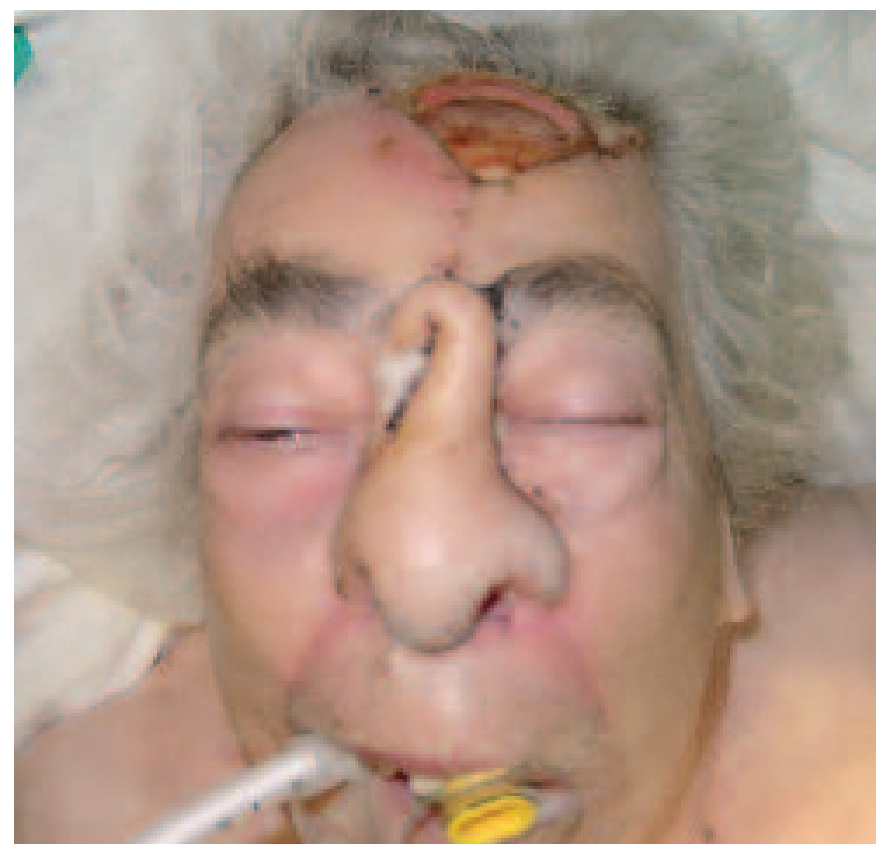

Fig. 6: Cuatro semanas de evolución; imágenes previas a la cuarta intervención gar mucho (pensamos en unas 5 horas de intervención) y dada la edad de la paciente, se decide llevar a cabo la cirugía reservando una cama en la Unidad de Cuidados Intensivos (UCI) por si fuese necesaria.

Un mes más tarde se procede a nueva intervención, justo el día en que la paciente cumple 90 años, practicándose ampliación de márgenes y estudio anatomopatológico peroperatorio que informa nuevamente de afectación de bordes, por lo que se procede a nueva ampliación, amputando en esta ocasión el remanente de tabique, de alas nasales y de la columela.

Una vez que la nueva Anatomía Patológica peroperatoria confirma que todos los márgenes están libres

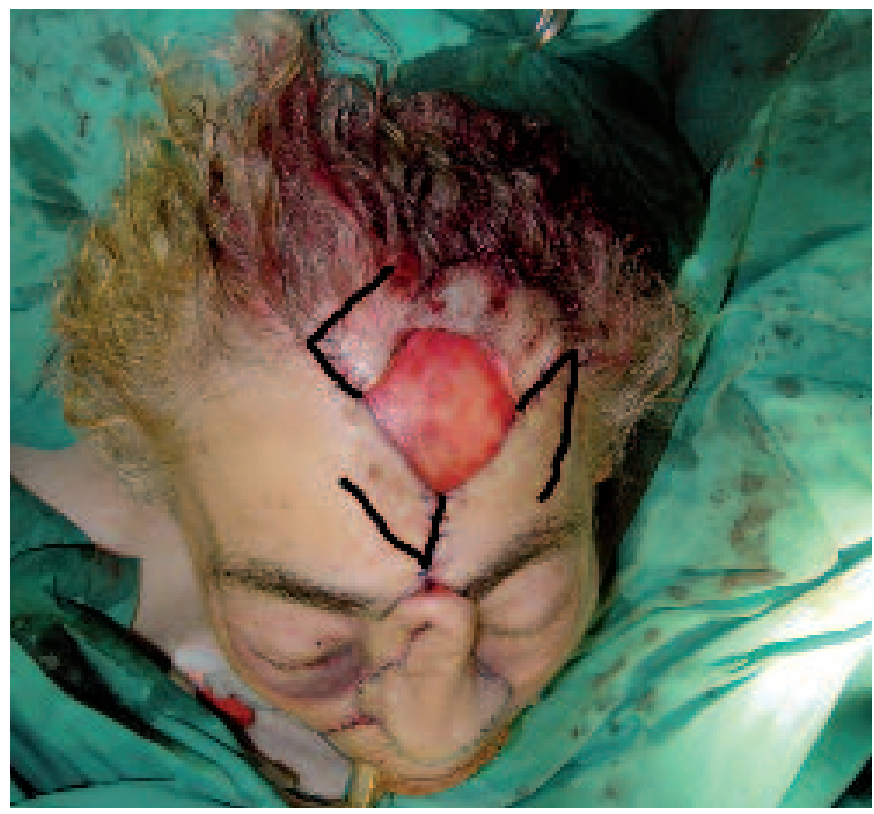

Fig. 7: Planteamiento del cierre del defecto de la zona dadora frontal mediante tres colgajos tipo Limberg. Líneas rotuladas mediante programa informático Adobe Photoshop 6.0 ${ }^{\circledR}$. 
se procede a la reconstrucción nasal total. Elevamos un colgajo septal de espesor total de base superior con irrigación a través de la arteria etmoidal anterior que se fija mediante alambre en su nueva posición y que consigue proyectar $4 \mathrm{~mm}$ en sentido anterior. Obtenemos un injerto óseo cortical de olécranon izquierdo mediante sierra oscilante con el que se elabora un soporte en L, mediante 2 piezas: una porción larga para dorso nasal y otra como poste a nivel columelar que se fijan entre si mediante alambre de 0.4. En la parte superior, el injerto se fija a los huesos nasales mediante un tornillo 2.0 de $4 \mathrm{~mm}$ y en la parte de la espina ósea se fija el poste mediante alambre de 0.4. Se procede a elevar dos colgajos nasolabiales de base superior (aproximadamente $12 \mathrm{~mm}$ de ancho en la parte craneal) y pivotados en el pliegue cutáneo nasolabial (3) que corresponde al margen de la exéresis tumoral, se voltean y suturan entre si para dar forro al poste óseo de la nueva columela y a las nuevas fosas nasales; la parte ósea del dorso nasal se cubre parcialmente con remanente de mucosa nasal. Para recrear los cartílagos alares se obtiene injerto cartilaginoso de la concha auricular derecha; se modelan dos cartílagos alares simétricos que se fijan mediante sutura de nylon $4 / 0$ a nivel de la parte más proyectada del injerto óseo y se dejan formando una curvatura natural encima del tejido subcutáneo de los dos colgajos nasolabiales. Finalmente se diseña y eleva un colgajo frontal tomando como referencia las medidas descritas por Burget (4-6); se sutura a los márgenes de la exéresis tumoral, en la piel de los colgajos nasolabiales que forma el forro de mucosa de las fosas nasales y en la parte superior de philtrum. La sutura de los colgajos se realiza con material reabsorbible en las

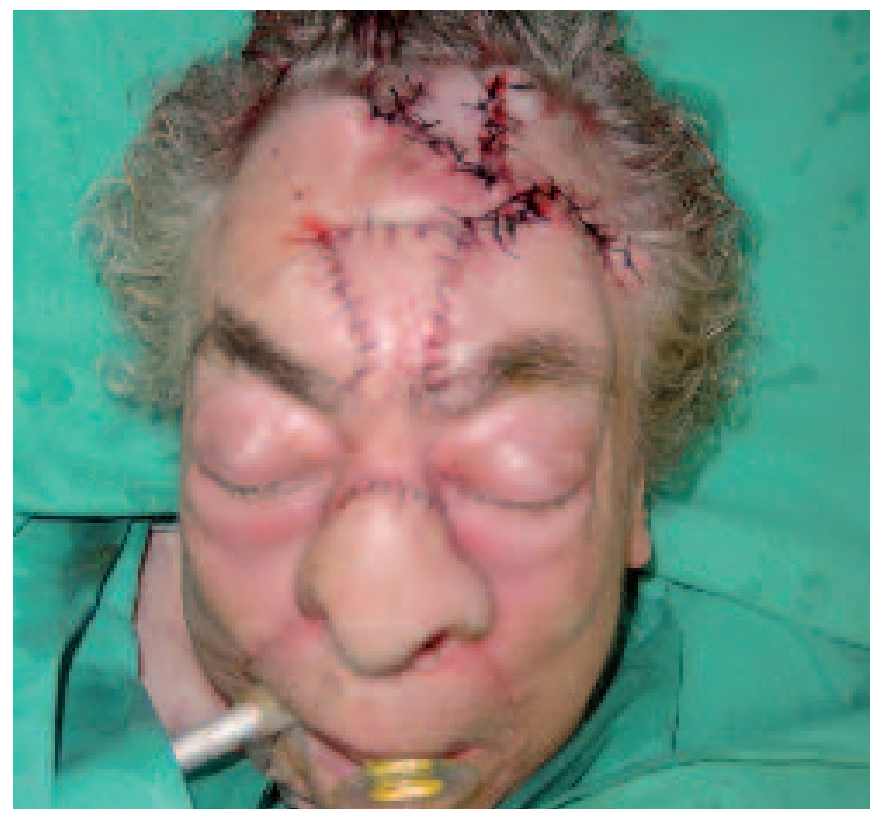

zonas de fosas nasales y con Nylon $4 / 0$ y $5 / 0$ en las zonas de márgenes cutáneos externos. Se procede a un abundante lavado con suero fisiológico de las fosas nasales y aspirado. Taponamiento nasal anterior con una unidad de Merocel® en cada fosa nasal. Colocación de Linitul ${ }^{\circledR}$ con gasa Furacinada a nivel del pedículo del colgajo frontal. La zona cruenta, consecuencia de la elevación del colgajo frontal, se cura mediante gasa furacinada como indica Burget en su libro, con cambios cada 24-48 horas en la habitación.

En total la intervención duró 4 horas y media, con buen control por parte del anestesista. La paciente estaba hemodinámicamente estable, por lo que se decide trasladarla a reanimación y posteriormente pasó a la planta sin necesidad de estancia en UCI. En el postoperatorio inmediato es importante mantener el cabezal elevado e instaurar cobertura antibiótica durante 7 días. A las 48 horas se procedió a la retirada de taponamiento nasal anterior, pero debido a la aparición de hemorragia nasal profusa se volvió a colocar y se mantuvo durante 5 días más. En total fueron 7 días de taponamiento nasal anterior. Durante las curas de la zona dadora del colgajo frontal se objetivó desecación del periostio y exposición de la cortical craneal, por lo que se decidió que en la siguiente intervención de autonomización del colgajo frontal se procedería al cierre de dicho defecto (Fig. 4-7).

A las cuatro semanas de postoperatorio, se procedió a la cuarta intervención quirúrgica en la que se practicó autonomización del colgajo frontal y elevación de tres colgajos tipo Limberg (7) alrededor del defecto frontal, con lo que se obtuvo el cierre de la zona dadora frontal. El colgajo frontal se readaptó en la zona superior del dorso nasal mediante Nylon de 5/0 y los

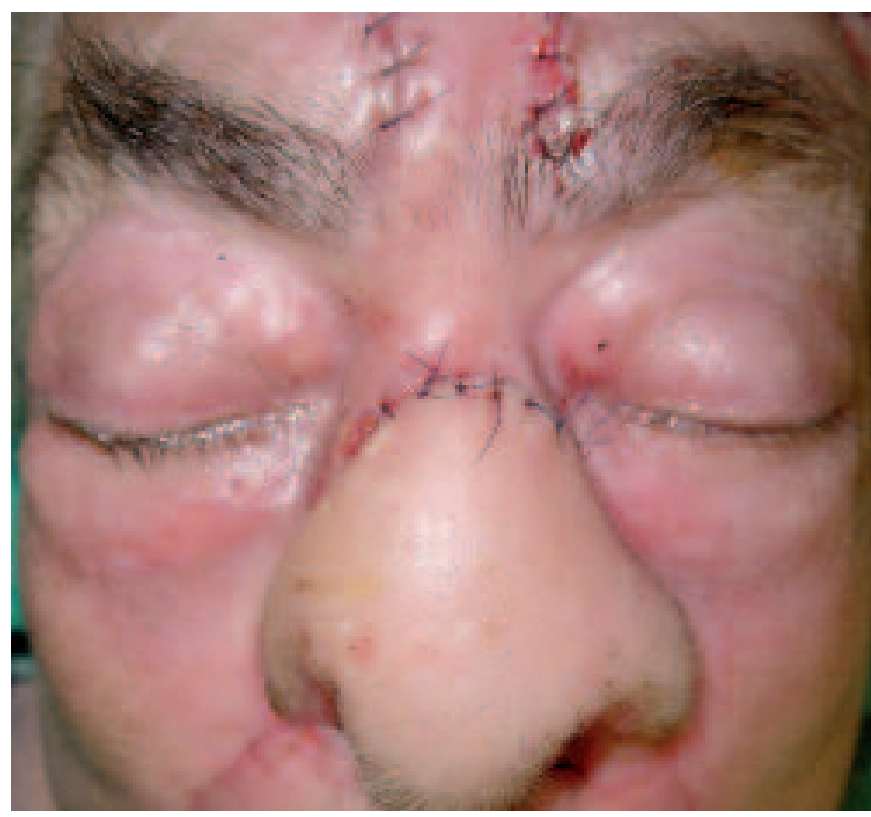

Fig. 8a-b: Aspecto postoperatorio inmediato: autonomización del colgajo frontal, readaptación a nivel de la parte superior del dorso nasal, cierre defecto zona dadora frontal. 


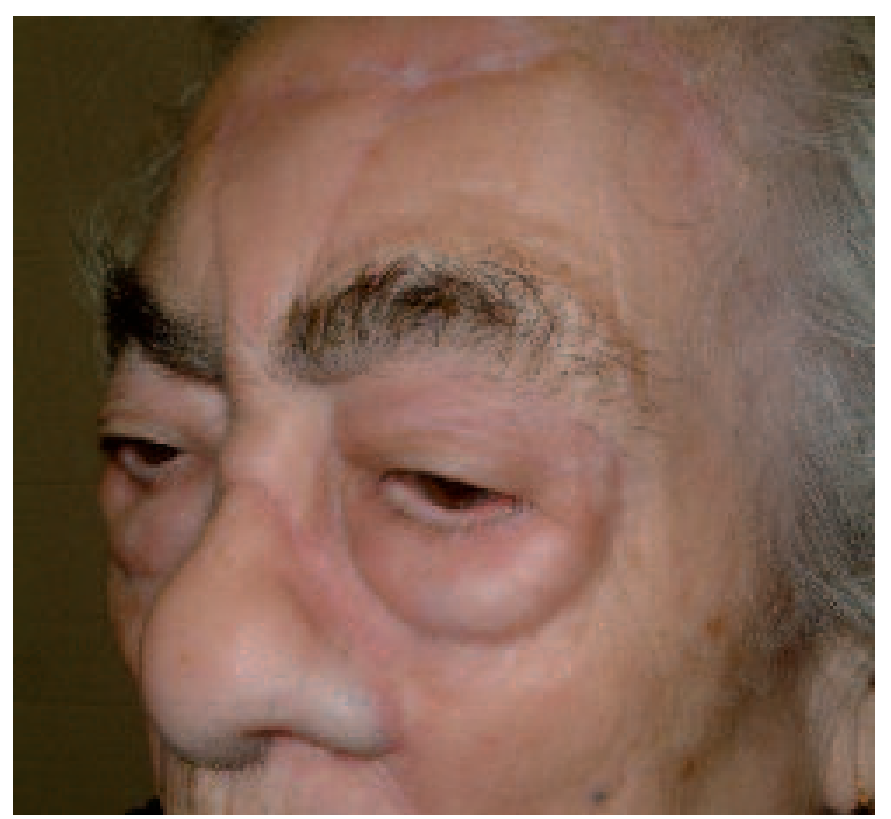

Fig. 9a-b: Aspecto a los 6 meses de la reconstrucción nasal total.

colgajos tipo Limberg se suturaron mediante seda $3 / 0$ y nylon 4/0. Esta intervención duró unas dos horas y media, sin ninguna complicación anestésica (Fig.8).

Un año después de la reconstrucción nasal, la paciente sigue controles periódicos en la consulta, con realización de TAC cada 6 meses y control clínico cada 3 meses no habiendo aparecido ninguna recidiva. No presenta tampoco dificultad respiratoria y la función anatómica y estética de su nueva nariz cumple con creces su cometido (Fig. 9).

\section{Discusión}

En los pacientes de edad avanzada siempre es preferible evitar grandes cirugías por el riesgo vital que esto supone; ésta era nuestra idea inicial, de ahí el seguimiento evolutivo que realizamos después de la exéresis y colgajo local realizado en la primera cirugía. Pero debido a la aparición de la recidiva y al hecho de presentar ésta una gran agresividad local nos decidimos por la cirugía oncológica radical con todo lo que esto suponía. Una vez realizada la amputación nasal y comentada la necesidad de nueva cirugía con el servicio de Anestesiología de nuestro hospital nos decidimos a realizar la reconstrucción con los riesgos añadidos que suponía la larga duración de la intervención prevista.

El mayor problema en reconstrucción nasal es con qué suplir el defecto de forro, armazón y cubierta cutánea; como indica Burget (2) debemos usar remanentes de mucosa o bien colgajos locales para el forro, injertos óseos para el dorso, injertos de cartílago para las alas nasales y cubierta cutánea con un colgajo frontal. Preferimos el uso del olécranon izquier-

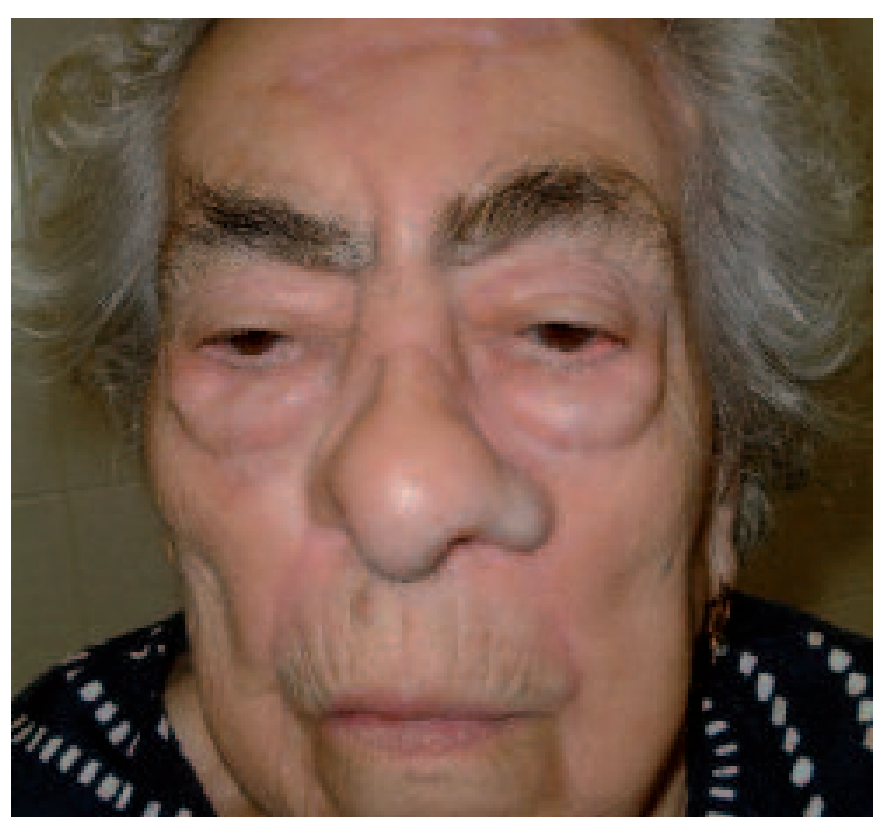

do como zona dadora del injerto óseo, en contra de los descrito por otros autores (2) que prefieren el cartílago costal, básicamente para evitar cualquier tipo de complicación respiratoria en la paciente dada su avanzada edad. Además la duración del proceso de obtención de la cortical ósea del olécranon es menor.

En nuestro caso creemos que seguir los pasos de reconstrucción del interior al exterior y evitar cualquier tipo de tensión a nivel de los colgajos ha supuesto evitar cirugía añadida por necrosis de alguno de los colgajos. Como complicación se nos presentó el hecho de que la zona dadora de la frente no granuló ni cerró por segunda intención, por lo que precisó que la cirugía de autonomización del colgajo fuera un poco más extensa para solucionar esta complicación.

Siempre se podría mejorar el resultado mediante cirugías posteriores orientadas a adelgazar el colgajo frontal y los colgajos nasolabiales que forman el forro en las narinas, pero como se ha comentado hemos intentado evitar al máximo el número de intervenciones dada la edad de la paciente y su patología previa.

Quizás fuimos demasiado atrevidos al retirar el taponamiento a las 48 horas de postoperatorio, tratándose de una reconstrucción nasal total con mucha movilización de tejidos; lo mejor hubiera sido de entrada dejar el taponamiento durante una semana.

Otros autores (2) usan a partir de la retirada del taponamiento un conformador de silicona para las narinas; en nuestro caso no nos fue posible conseguirlo en el hospital, no obstante el resultado fue igualmente satisfactorio.

Otra cuestión a mejorar es el pelo que aparece en la zona más distal del colgajo frontal y que corresponde a la línea de implantación del pelo; su solución es la 
depilación láser, pero en nuestro caso, dada la edad de la paciente, su pelo no presenta pigmentación alguna por lo que el láser no es útil. Existe la posibilidad de eliminar los folículos pilosos en el momento de elevar el colgajo frontal, pero en nuestro caso no se hizo para no comprometer la vascularización de la parte distal del colgajo destinada a recrear alas nasales y columela.

\section{Conclusiones}

El mayor problema en la reconstrucción nasal está en con qué suplir el defecto de forro, armazón y cubierta cutánea.

En los injertos óseos para el dorso es fundamental el contacto hueso-hueso para la correcta consolidación, es decir que es de vital importancia disponer de un remanente de huesos nasales para fijar el injerto de dorso.

Es fundamental evitar cualquier tipo de tensión en los colgajos para evitar zonas de necrosis parcial y adelgazar al máximo los colgajos nasolabiales para evitar un paso estrecho en las narinas, sin comprometer su vascularización.

Creemos importante mantener el taponamiento nasal anterior durante una semana. No nos parece imprescindible usar conformador de silicona para mantener la apertura de las narinas.

En pacientes de edad avanzada creemos importante solucionar el problema en la primera cirugía, es decir, llevar a cabo una cirugía oncológica amplia, asegurando unos márgenes correctos para evitar posi- bles recidivas, aunque esto suponga una resultado estético menor. El hecho de sufrir alguna recidiva, como en el caso que presentamos, supone proceder a una serie de intervenciones muy agresivas que no todos los pacientes de edad avanzada pueden llegar a superar.

\section{Dirección del autor}

Dr. Jordi Serracanta i Doménech.

Hospital Universitari de Bellvitge.

Carrer Feixa Llarga s/n. L’Hospitalet de Llobregat.

Barcelona. España

e-mail: jserracanta@hotmail.com

Bibliografía

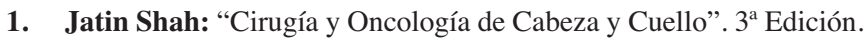
Editorial Elsevier. 2004. (1) Pp: 1-2.

2. Cervelli V, Bottini DJ, Gentile P, Fantozzi L, Arpino A, Cannata C, Fiumara L, Casciani CU.: "Reconstruction of the nasal dorsum with autologous rib cartilage". Ann Plast Surg. 2006, 56(3):256.

3. Demir Z, Ozdil K, Karamursel S, Yuce S, Oktem F, Celebioglu S.: "Reconstruction of the columella with bilateral nostril sill flaps". Ann Otol Rhinol Laryngol. 2006,115(3):239.

4. Burget G.C., Menick F.J. "Aesthetic Reconstruction of the Nose". Editorial Mosby. Pp: 313-314.

5. Singh GC, Withey S, Butler PE, Kelly MH.: "Forehead flap method for total nasal reconstruction". Asian J Surg. 2006, 29(2):101.

6. Sakurai H, Takeuchi M, Fujiwara O, Soejima K, Yamaki T, Kono T, Nozaki M.: "Total face reconstruction with one expanded free flap". Surg Technol Int. 2005;14:329.

7. Jackson I.T.: "Colgajos locales en la reconstrucción de cabeza y cuello" Salvat Editores S.A. Pp: 87-188. 


\section{Comentario al trabajo uReconstrucción nasal total: a propósito de un casou}

\section{Dr. Francisco Javier Gabilondo. Jefe de Servicio de Cirugía Plástica. Hospital de Cruces. Baracaldo. Vizcaya. España}

Aprovechando la lectura del caso clínico de los Dres. Serracanta Doménech y cols. sobre la reconstrucción nasal diferida, quiero, además de felicitarles por el resultado, rendir homenaje a dos cirujanos plásticos españoles de reconocido prestigio: Drs. Lorenzo Mir y Mir; y Benito Vilar Sancho, recordando con sus "frases lapidarias", sus enseñanzas.

En el caso que nos ocupa analizamos dos aspectos complementarios que interesa plantear por separado:

El concepto de resección incompleta en cirugía oncológica. Don Lorenzo Mir y Mir siempre insistía en la incorrección de las "cachectomías" en la cirugía tumoral que dejando bordes invadidos confundía la resección incompleta con la recidiva, como los autores nos advierten en su trabajo. Siempre es más inocuo un bisturí experto que una resección tímida e incompleta de un tumor.

La reconstrucción nasal, a mi juicio, no sólo es correcta sino brillante, aun siendo diferida en una paciente que así lo ha requerido por su patología asociada y su edad. Si algo tiene nuestra especialidad de quehacer artesanal, es la elección personalizada de la técnica adecuada a las circunstancias del paciente dentro de las múltiples soluciones técnicas correctas, entre las cuales suelen ser fundamentos del "sentido común" la sencillez y seguridad, que nos llevan a elegir un procedimiento individualizado. En este caso, siendo en general deseable la reconstrucción inmediata, la paciente, además al apreciar el tamaño y la complejidad del defecto, suele ser más realista y acepta siempre mejor el resultado de una reconstrucción diferida aun siendo igual el aspecto al de la inmediata.

Técnicamente, resulta muy didáctico la descripción en tres planos de forro, armazón y cobertura cutánea tal como nos describen los autores; y citando de nuevo a nuestros maestros respecto al armazón "todo lo que sujeta un tabique (septo nasal) puede mantenerlo una viga adecuada" (Dr. Vilar Sancho).

En mi criterio y respecto al trabajo agradecería a los autores que añadiesen una imagen del aspecto de los orificios nasales para apreciar el tamaño de las narinas como imagen "c" en la figura 9; para, como lo hacen en la figura 5b, ilustrar la importancia de un tamaño adecuado del colgajo en esta reconstrucción tridimensional, pues los colgajos pequeños por retracción suelen plantear problemas en el calibre del orificio natural que a veces no se resuelven ni con conformadores. Circunstancia que en este caso no ha sucedido a pesar de la ausencia del mismo, tal como ellos nos indican gracias al tamaño del colgajo, suficiente para un perímetro adecuado de la narina nasal.

Reiterando mis felicitaciones por el excelente trabajo a sus autores, espero que con estos amigables comentarios podamos debatir estos aspectos recordando a nuestros ilustres rinólogos Mir y Mir (†) y Vilar Sancho.

\section{Respuesta al comentario del Dr. Francisco Javier Gabilondo}

\section{Dr. J. Serracanta Domènech}

Mi más sincero agradecimiento al Dr. Gabilondo por sus elogios en el comentario a nuestro trabajo publicado en el presente número.

Es un honor recibir tales elogios por la labor realizada por mi equipo en un caso clínico que se nos planteó muy complicado en su momento y que supimos solucionar gracias a la correcta elección de las técnicas usadas, adecuándose éstas a los medios disponibles; sumándole a todo una buena dosis de sentido común.

Así el primer tiempo oncológico fue incompleto por no disponer de estudio anatomopatológico per-operatorio, del cual sí dispusimos en la segunda cirugía y nos permitió realizar una correcta cirugía oncológica con márgenes libres; condición indispensable antes de iniciar la etapa reconstructiva.
Dada la patología de base de la paciente era necesario evitar tiempos quirúrgicos muy prolongados que pudiesen aumentar la morbimortalidad de la cirugía, de ahí la reconstrucción diferida. Como bien señala el Dr. Gabilondo en su comentario la reconstrucción diferida permite al paciente ser más realista con el trabajo realizado, pues después de "vivir" un tiempo con un gran defecto estético valora mucho más el resultado obtenido mediante la reconstrucción.

Añado nuevas fotos tomadas en la actualidad del caso, ya son 2 años y medio posteriores a la cirugía, y puede apreciarse muy bien el diámetro existente de las narinas y como se ha mantenido la proyección adecuada de la pirámide nasal.
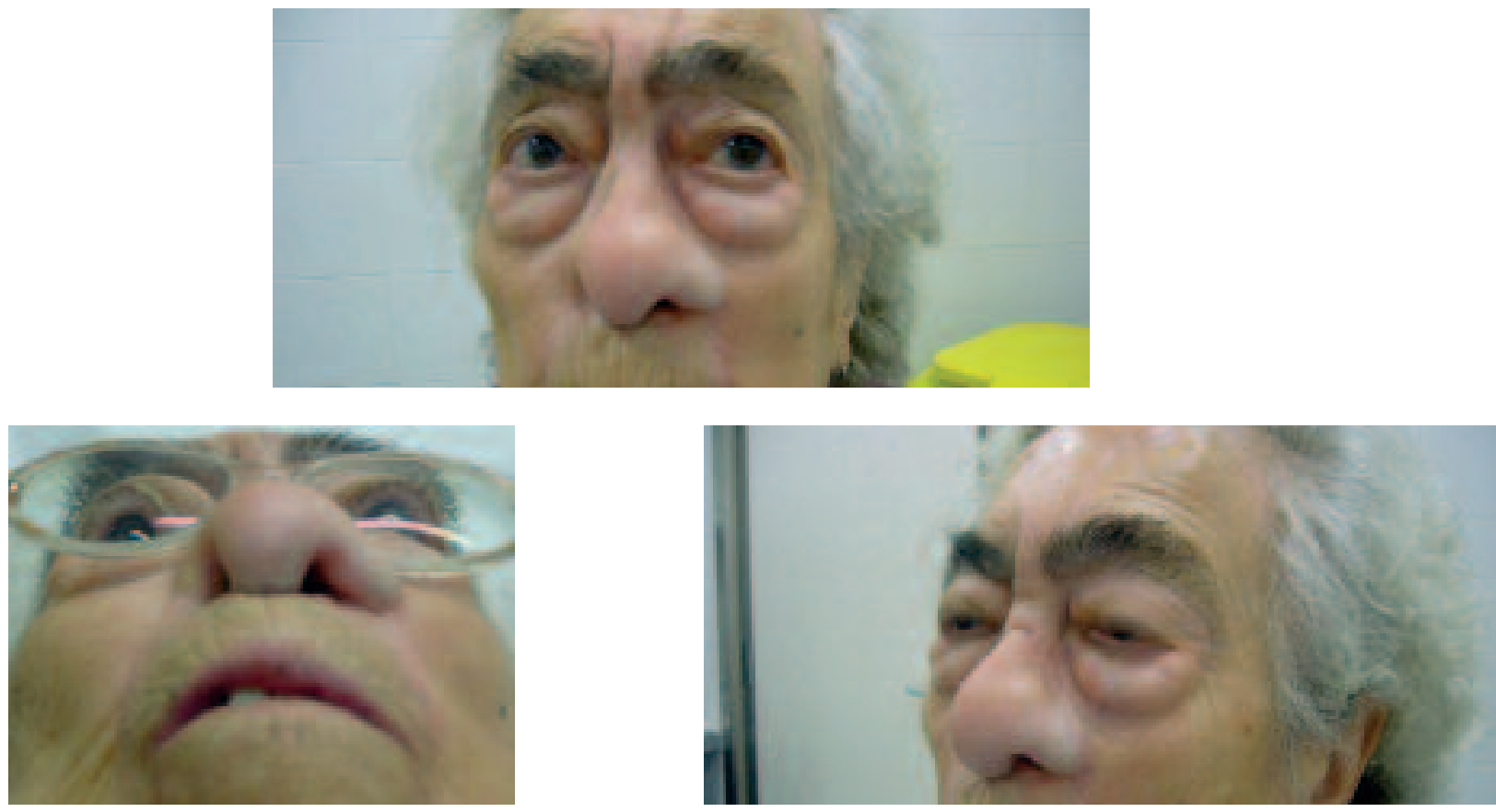